\title{
Treatment of episcleritis
}

\section{A double-blind trial comparing betamethasone $\mathrm{o} \cdot \mathrm{I}$ per cent., oxyphenbutazone ro per cent., and placebo eye ointments}

P. G. WATSON, D. A. R. MaKAY, R. S. GLEMETT, AND P. WILKINSON Cambridge

Simple episcleritis is a very variable condition, especially in the severity and duration of $\frac{\circ}{2}$ individual attacks which may be acute and short, apparently responding very rapidly to $\vec{z}$ drug therapy, or may proceed to a chronic or repeatedly recurrent condition. Nodular episcleritis follows a similar but more prolonged course.

Local corticosteroids, either as drops or ointment, are widely used and have replaced $\underset{\mathbb{\Phi}}{\square}$ older methods of treatment. Their efficacy is accepted, although so far as it is known thog has never been proved by double-blind trials.

Oxyphenbutazone (Tanderil) has been shown to be effective in episcleritis when adminto stered orally, when it produces the same effect as systemic corticosteroids without the rebound of symptoms and signs on withdrawal of treatment (Watson, Lobascher, Sabiston, $\overline{0}$ Lewis-Faning, Fowler, and Jones, I966). Uncontrolled observations indicate that it is also effective in some patients with scleritis.

\section{Patients, material, and methods}

$4^{8}$ patients with either a first or recurrent attack of episcleritis, attending the Out-patients Clinic at Moorfields Eye Hospital, were randomly allocated to treatment with either betamethasone $0 \cdot 1$ per. cent. ointment, oxyphenbutazone ro per cent. ointment, or a placebo ointment. The dispensing list was stratified for the presence or absence of nodules and for whether or not steroids had been prescribed for the present attack.

The ointments were made as nearly identical as was possible galenically, and dispensed in matching 0 tubes. Instructions were given to the patient to apply the ointment to the affected eye three times a day for 3 weeks.

At the initial attendance the severity of the disease was assessed by rating pain and injection of the conjunctiva, episclera, and sclera, on a o to 3 scale: $0=$ absent, $\mathrm{I}=$ mild, $2=$ moderate, and $3=\sigma$ severe. Nodules were rated as present (3), obvious (6), and confluent (10), the score being multiplied $\tilde{O}$

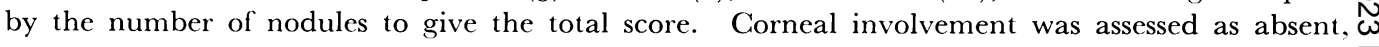


as to the diagnosis of episcleritis arose during the course of the attack the patient was withdrawn. Initial investigations included haemoglobin, white cell count, erythrocyte sedimention rate, RA latex $\stackrel{\Phi}{\longrightarrow}$ test for rheumatoid factor, serum uric acid, and Wassermann reaction; more specific tests were performed if indicated.

Patients were seen for assessment at weekly intervals for 3 weeks. Any untoward reaction was recorded as it arose. 


\section{Results}

The three treatment groups, betamethasone, oxyphenbutazone, and placebo, are referred to in the text as " $\mathrm{B}$ ", " $\mathrm{O}$ ", and "P" groups respectively.

Of the 48 patients admitted to the trial, five were discarded because of failure to attend the follow-up examinations. There were five withdrawals who have not been included in the analysis: three in the "O" group (due to failure to respond to the treatment prescribed, skin sensitivity, and scleritis), and the other two in the placebo group (due to scleritis and an allergy to the ointment base).

The age and sex distribution of the remaining 38 cases are given in Table I.

Table I Age and sex distribution-all patients

\begin{tabular}{|c|c|c|c|c|c|}
\hline \multirow{2}{*}{ Group } & \multicolumn{3}{|c|}{ Sex } & \multicolumn{2}{|c|}{ Age (yrs) } \\
\hline & $M$ & $F$ & Total & Range & Mean \\
\hline B & 8 & 7 & I 5 & $2 \mathrm{I}-6 \mathrm{I}$ & $4 I \cdot 9$ \\
\hline $\mathrm{O}$ & 3 & 7 & IO & $17-5^{8}$ & $34 \cdot 4$ \\
\hline$P$ & 9 & 4 & I 3 & 19-55 & $4^{2 \cdot I}$ \\
\hline Total & 20 & I 8 & $3^{8}$ & I $7-6$ I & $39 \cdot 5$ \\
\hline
\end{tabular}

Males formed 55 per cent. of the patients and the ratio in each treatment group varicd significantly $(0.05>\mathrm{P}>0.02)$, females preponderating in the "O" group and males in the "P" group.

Four patients had a positive RA latex test, one in the " $B$ " group, one in the " $O$ " group, and two in the " $P$ " group. One patient in the " $B$ " group had proven rheumatoid arthritis.

Before assessing the individual parameters, the three groups were analysed for comparability with regard to first or second attack, presence or absence of nodules, length of history, presence of associated disease, treatment with steroids, and numbers seen in the first week of attack. No difference was demonstrated statistically with regard to any of these factors which might affect the progress of the condition in each group.

EPISCLERAL INJECTION

The mean score, together with percentage improvement is given in Table II.

Table II Mean scores with percentage improvement-episcleral injection

\begin{tabular}{|c|c|c|c|c|c|}
\hline \multirow{2}{*}{ Group } & \multirow{2}{*}{ No. } & \multicolumn{4}{|l|}{ Day } \\
\hline & & o & 7 & I 4 & $2 \mathrm{I}$ \\
\hline B & 15 & $4 \cdot 27$ & I 60 (63 per cent.) & 0.40 ( $8 \mathrm{I}$ per cent.) & 0.20 (95 per cent.) \\
\hline $\mathrm{O}$ & 10 & $3 \cdot 60$ & 0.90 (75 per cent.) & 0.70 (81 per cent.) & 0.20 (94 per cent.) \\
\hline $\mathbf{P}$ & I 3 & $3 \cdot 3 \mathrm{I}$ & I 69 (5 1 per cent. $)$ & I $\cdot$ oo (7o per cent.) & 0.54 (84 per eent.) \\
\hline
\end{tabular}

Patients in the " $B$ " group had the highest initial score, but the differences between the three groups were not statistically significant. By Day 7 a $5^{\circ}$ per cent. improvement had occurred in the "P" group, and this had increased to 84 per cent. by Day $2 \mathrm{I}$, but this was 
less than the improvement in both the "O" and "B" groups particularly at Day 7 (this $\frac{0}{3}$ observation was not significant). By Day $2 \mathrm{I}$ resolution was practically complete in all $\frac{\text { ㅇ }}{}$ groups.

Examination of patients free from episcleral injection on the respective assessment days $\frac{?}{7}$ is shown in Table III.

Table III Proportion of patients free of inflammation at each assessmentepiscleral injection

\begin{tabular}{|c|c|c|c|c|}
\hline \multirow{2}{*}{ Group } & \multirow{2}{*}{$\begin{array}{l}\text { No. who } \\
\text { could improve }\end{array}$} & \multicolumn{3}{|l|}{ Cleared by Day } \\
\hline & & 7 & 14 & $2 \mathrm{I}$ \\
\hline B & I 5 & 4 (27 per cent.) & I I (73 per cent.) & I 3 (87 per cent.) \\
\hline $\mathrm{O}$ & I I * & 6 (54 per cent.) & 7 (54 per cent.) & 8 (73 per cent.) \\
\hline $\mathrm{P}$ & 13 & 2 (I 5 per cent.) & 8 (62 per cent.) & I I (85 per cent.) \\
\hline
\end{tabular}

* Includes one patient who failed to respond to treatment and was later withdrawn from the trial.

By Day 7, resolution was complete in six out of eleven patients in the "O" group com-

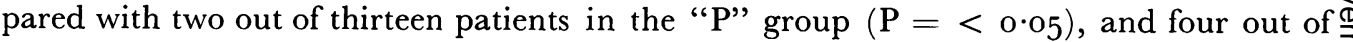
fifteen patients in the "B" group. At Day I 4 the improvement was similar in all groups and also at Day $2 \mathrm{I}$.

CONJUNGTIVAL INJEGTION

The conjunctiva is sometimes congested long after the episcleritis has cleared. Analysĭ of this parameter was therefore undertaken but the results were almost identical to those found for episcleral injection.

NODULES

The number of patients with nodules at each assessment is given in Table IV.

Table IV Number of patients with nodules

\begin{tabular}{|c|c|c|c|c|c|c|c|c|c|c|c|c|}
\hline \multirow{2}{*}{ Type of nodule } & \multicolumn{4}{|c|}{ Betamethasone } & \multicolumn{4}{|c|}{ Oxyphenbutazone } & \multicolumn{4}{|c|}{ Placebo } \\
\hline & o & 7 & 14 & $2 \mathrm{I}$ & o & 7 & I 4 & $2 \mathrm{I}$ & o & 7 & 14 & 21 \\
\hline Just present & I & - & - & - & - & $3^{*}$ & - & - & I & $5^{*}$ & 3 & I \\
\hline Obvious & 2 & $\mathbf{I}$ & - & - & $4^{*}$ & I & I & - & $4^{*}$ & - & - & 一 \\
\hline Large and confluent & $\mathbf{I}$ & 一 & - & - & 一 & 一 & 一 & - & 一 & - & - & - \\
\hline Total (patients) & 4 & I & 一 & - & 3 & 3 & I & - & 4 & 4 & 3 & I \\
\hline
\end{tabular}

*Patients with two nodules

Nodules were present in eleven patients (29 per cent.). In three out of four patients in the " $B$ " group, the nodules had resolved by Day 7, whereas in the " $O$ " and "P" groups they persisted. By Day $2 \mathrm{I}$ all the nodules in the " $\mathrm{B}$ " and " $\mathrm{O}$ " groups had cleared but one in the " $P$ " group had persisted.

The number of patients with nodules is not sufficient to allow a reliable statistical comparison, but the trend suggests that resolution occurred earlier in those patients receiving betamethasone. 
CORNEAL INVOLVEMENT

This was recorded as either present and inactive or present and active. Stromal oedema was recorded in four patients in the "B" group (three inactive and one active), two patients in the "O" group (one inactive and one active), and two patients in the "P" group (both active). The corneal changes had disappeared in all of the patients by Day 7 , with the exception of one patient in the "P" group who was withdrawn from the trial for systemic treatment.

PAIN

This was not a prominent feature of the disease in this series and in all the patients pain was confined to the affected eye. At the initial assessment three patients in the " $\mathrm{B}$ " group, six in the "O" group, and two in the "P" group were pain-free. Of those who complained of pain, half the patients in the "P" group were symptom-free by Day 7 and the remainder became so by Day $2 \mathrm{I}$. The degree of improvement was similar in both the " $\mathrm{B}$ " and " $\mathrm{O}$ " groups.

\section{Discussion}

This series demonstrates that episcleritis is a self-limiting disease and that a 50 per cent. improvement can be expected in 7 days. Even without treatment well over 80 per cent. of patients will be free of all traces of the condition within 2 I days. In view of this the question arises whether drug therapy is necessary. It may be difficult to deny a patient therapy at the initial attendance and therapy is probably necessary for the more refractory nodular form of the disease. No one would deny that steroid preparations, whether given topically or systemically, are effective anti-inflammatory agents and often prescribed for this purpose.

Comparison of the three groups shows, however, the difficulty of conclusively proving the efficacy of a proven anti-inflammatory drug in a self-limiting disease. After 7 days' treatment the improvement in those patients who received oxyphenbutazone was significantly greater than in those who received a placebo. No other comparison attained the accepted level of significance, although in the early stages of the disease the findings suggested that betamethasone is superior to placebo (Figure).

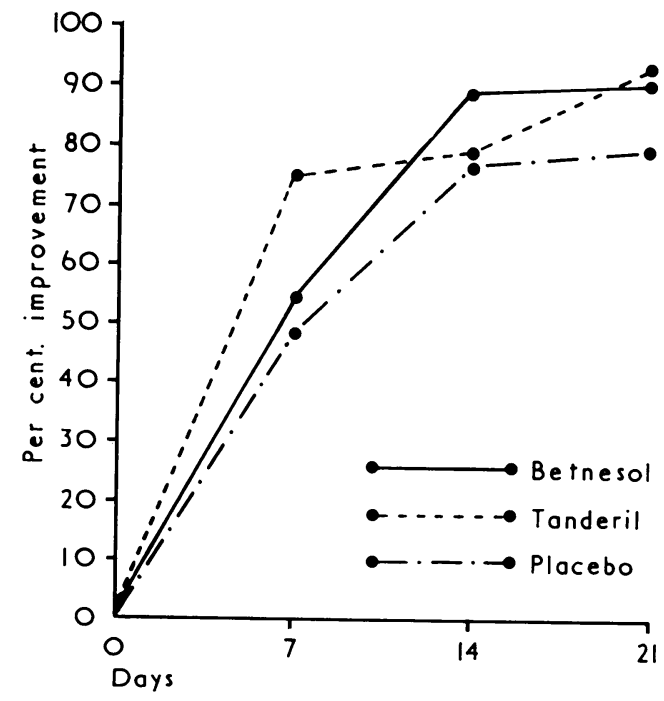

FIGURE Comparison of rate of improvement of all signs and symptoms with two active preparations and placabo. The more rapid improvement with Tanderil in the first week is significant. 
The number of patients with nodular disease was insufficient to undertake a reliable $\frac{\partial}{3}$ statistical comparison, but the trend suggested that betamethasone was superior to $\frac{\mathrm{o}}{.}$ oxyphenbutazone which was more effective than placebo.

In a self-limiting disease, a drug is only of benefit during the early stages when by its pnarmacological action it can aid resolution.

In order to prove conclusively that a drug is active during this period, frequent follow-up $\frac{\overline{\bar{p}}}{\overrightarrow{0}}$ assessments would be necessary, which is impracticable for those attending an out-patients clinic.

The indications are that both topical betamethasone and topical oxyphenbutazone aid $\overrightarrow{0}$ resolution, in a manner similar to systemic therapy with prednisolone and oxyphenbutazone (Watson and others, 1966).

Topical oxyphenbutazone is to be preferred to systemic administration as the systemic $\frac{0}{0}$. side-effects of pyrazole drugs are avoided. Steroids may also be given topically or syste- y mically, although neither route is free from complications and both should be avoided if $\exists$ there is a satisfactory alternative. If therapy is indicated in episcleritis, it would appear, on the basis of this study, that topical oxyphenbutazone is the most satisfactory agent available, even if it has to be administered as an ointment.

\section{Summary and conclusion}

This report presents the results of a controlled double-blind study to compare the efficacy of betamethasone 0.1 per cent., oxyphenbutazone io per cent., and a placebo in the trea ment of episcleritis. Patients were randomly allocated to one of the three treatments from stratified dispensing list. The ointment was applied three times a day for 3 weeks. Pa ients were assessed by numerical scoring of pain, injection of the episclera, conjunctiva, and sclera, corneal involvement, and presence and size of nodules, at weekly intervals for 3 weeks.

A total of 38 patients was suitable for comparison of treatment. The study demonstrates that episcleritis is a self-limiting disease lasting approximately $2 \mathrm{I}$ days, and that a $5^{\circ}$ per cent. improvement occurs within the first 7 days. Therapy with either oxyphenbutazone or betamethasone aided resolution, suggesting that if therapy is indicated either treatment is suitable.

The authors would like to thank the Consultant Staff at Moorfields Eye Hospital, London, and other eye surgeons for permission to use their patients for this trial.

\section{References}

WATSON, P. G., LOBASChER, D. J., SABISTON, D. W., LEWIS-FANinG, E., FOWLER, P. D., and JONES, B. R. (ig66) Brit. J. Ophthal., 50, 463 